\title{
Differential Pulse Voltammetric Studies on Lamivudine: An Antiretroviral Drug
}

\author{
Katia Christina Leandro ${ }^{1}$, Josino Costa Moreira ${ }^{1}$, Pércio Augusto Mardini Farias ${ }^{2}$ \\ ${ }^{1}$ Fundação Oswaldo Cruz, Rio de Janeiro, Brazil \\ ${ }^{2}$ Department of Chemistry, Pontifícia Universidade Católica do Rio de Janeiro, Rio de Janeiro, Brazil \\ Email: pfarias@puc-rio.br
}

Received February 2, 2013; revised March 6, 2013; accepted May 7, 2013

Copyright (C) 2013 Katia Christina Leandro et al. This is an open access article distributed under the Creative Commons Attribution License, which permits unrestricted use, distribution, and reproduction in any medium, provided the original work is properly cited.

\begin{abstract}
Lamivudine (also known as 3TC) is a dideoxynucleoside analogue, which undergoes intracellular phosphorylation in the putative active metabolite, lamivudine triphosphate. Lamivudine triphosphate prevents HIV replication by competitively inhibiting viral reverse transcriptase. Lamivudine has been extensively used in the treatment of HIV patients owing to its antiretroviral activity. For the determination of lamivudine in pharmaceuticals, an analytical methodology using voltammetry was developed. Lamivudine was reduced at a hanging mercury drop electrode (HMDE) at $-1.16 \mathrm{~V}$ vs $\mathrm{Ag} / \mathrm{AgCl}$ at $\mathrm{pH} 2.0$. The influence of electroanalytical parameters such as scan rate $\left(20 \mathrm{mV} \cdot \mathrm{s}^{-1}\right)$, amplitude $(50 \mathrm{mV})$, nature of the support electrolyte (Clark-Lubs), and $\mathrm{pH}$ (2.0) on the voltammetric signal was optimized. Under these optimized conditions, the method had been validated using pharmaceutical formulations. The lamivudine peak current varied linearly with its concentration from 1.15 to $10.40 \mathrm{mg} \cdot \mathrm{L}^{-1}$, detection and determination limits of 0.46 and 1.0 $\mathrm{mg} \cdot \mathrm{L}^{-1}$, respectively, and recovery of $95.15 \%$ with a relative standard deviation of $1.10 \%$.
\end{abstract}

Keywords: Lamivudine Determination; HIV; Antiretroviral Drugs; Voltammetric Analysis

\section{Introduction}

Lamivudine (3TC, 2'-deoxy-3'-thiacytidine) is extensively used in treatments of acquired immune deficiency syndrome (AIDS). Lamivudine is a nucleoside reverse transcriptase inhibitor structurally related to cytosine with activity against retroviruses, including HIV. After oral administration, lamivudine is well absorbed and has good bioavailability (mean absolute bioavailability $>80 \%$ in adults and $68 \%$ in infants and children) [1]. Lamivudine is not significantly metabolized and is eliminated primarily as an unchanged drug via the kidneys [2].

Lamivudine is phosphorylated to its putative active metabolite, lamivudine-5'-triphosphate (lamivudine triphosphate), initially by deoxycytidine kinase and then by other human cellular kinase enzymes. Lamivudine triphosphate inhibits viral reverse transcriptase by competing with 2'-deoxycytidine-5'-triphosphate for incorporation into HIV DNA. Because lamivudine triphosphate lacks the 3'-hydroxyl group required for nucleic acid replication, viral DNA chain elongation is terminated and HIV replication is prevented [3]. It has been shown not to be a substrate for cytidine deaminase, which would convert it to the inactive uridine derivative, or a substrate for phos- phorylase. The half-life in infected cells is 10 to 14 hours [4].

For the therapeutic uses, lamivudine is available in capsules containing 100 or $150 \mathrm{mg}$ and in syrups of 10 $\mathrm{mg} \cdot \mathrm{mL}^{-1}$ (for pediatric use).

Several high-performance liquid chromatographic (HPLC) [5-10] and spectrophotometric $[11,12]$ methods for the determination of lamivudine in biological fluids have been published. Recently, electroanalytical methods $[13,14]$ for lamivudine determination in human serum and plasma have been developed. The present work reports investigations on the electrochemical behavior of lamivudine in Clark-Lubs buffer (pH 2.0) electrolyte at HMDE and proposes an alternative approach with validation of the determination of trace amounts of lamivudine in pharmaceuticals.

\section{Experimental}

\subsection{Apparatus}

Cyclic and differential pulse voltammograms were obtained with a Metrohm Voltammetric System, Model 757 VA Computrace. The working electrode was a hanging 
mercury dropping electrode (HMDE), an $\mathrm{Ag} / \mathrm{AgCl}$ as the reference electrode and platinum as the auxiliary electrode. All pH measurements were made with a Micronal B474 pH-Meter using a combined Ag/AgCl—glass electrode.

\subsection{Materials and Reagents}

Water purified in a Milli-Q system (Millipore) was used for all dilutions and sample preparations. All chemicals were of analytical reagent grade. Lamivudine standard was used as received by the Instituto Nacional de Controle de Qualidade em Saúde-Brazil (INCQS-lot L1, $100.2 \%)$. Stock solution of lamivudine $\left(229 \mathrm{mg} \cdot \mathrm{L}^{-1}\right)$ was prepared by dissolving $22.9 \mathrm{mg}$ of lamivudine into water until a combine volume of $100 \mathrm{~mL}$ was reached. The 0.2 M Clark-Lubs buffer ( $\mathrm{pH}$ 2.0) was also prepared in water. The $\mathrm{pH}$ of $0.04 \mathrm{M}$ Britton-Robinson buffer ( $\mathrm{pH} 2.0$ - 11.0) was controlled by the addition of hydroxide sodium solution.

\subsection{Validation Method}

The developed voltammetric method was validated according to international guidelines for bioanalytical methods, including stability of analyte, determination of specificity and selectivity, calibration curve, detection and determination limits, accuracy, and inter-day and intraday precision $[15,16]$.

\subsubsection{Stability}

For verification of current peak lamivudine stability were utilized aliquots of the stock solution of lamivudine from pharmaceutical form $\left(22.9 \mathrm{mg} \cdot \mathrm{L}^{-1}\right.$ in $2 \mathrm{M} \mathrm{HCl}$ at $\left.25^{\circ} \mathrm{C}\right)$ prepared two weeks prior to the experiment. These aliquots were added in an electrochemistry cell containing 0.2 M Clark-Lubs buffer solution ( $\mathrm{pH} 2.0)$ and analyzed by method voltammetric proposed. These voltammograms results were compared with those obtained from stock solution of lamivudine when measured immediately after your preparation.

\subsubsection{Specificity and Selectivity}

Both specificity and selectivity describe the extent to which a method uniquely reacts to a selected element. The major sources of interferences are likely to be coexisting ions and organic surfactants. These species could result in either new reduction peaks or the overlap with the lamivudine peak, thus obscuring the measurement. Then selectivity studies must be performed in order to investigate the effect of potential ions and compound interferents. The presence of zidovudine (AZT) and zalcitabine (DDC) compounds were investigated as possible interferents in the lamivudine $\left(100 \mathrm{mg} \cdot \mathrm{L}^{-1}\right.$ in pharmaceutical form) determination by method voltammetric pro- posed. The effect of $\mathrm{Fe}^{3+}, \mathrm{Cu}^{2+}, \mathrm{Zn}^{2+}, \mathrm{Li}^{+}, \mathrm{Pb}^{2+}, \mathrm{Cd}^{2+}$, $\mathrm{Ni}^{2+}, \mathrm{Co}^{2+}$ and $\mathrm{Cr}^{3+}$ ions in the free lamivudine also was verified (see results in 3.4. Validation Method).

\subsubsection{Calibration Curve, Detection and Determination Limits}

Although voltammetry is well known for benefiting from a wide linear concentration range, this parameter was evaluated by checking the linear regression coefficient of two calibration curves constructed with standard lamivudine additions. The differential pulse voltammograms, ranging from -1.00 to $-1.25 \mathrm{~V}$, were obtained by varying the lamivudine concentration from 1.15 to $10.40 \mathrm{mg} \cdot \mathrm{L}^{-1}$. The other experimental conditions used were Clark-Lubs buffer ( $\mathrm{pH}$ 2.0) as the supporting electrolyte, a scan rate of $20 \mathrm{mV} \cdot \mathrm{s}^{-1}$ and a pulse amplitude of $50 \mathrm{mV}$. Using the same conditions, the detection and determination limits of lamivudine in pharmaceutical form were experimentally determinate (see results in Table 1).

\subsubsection{Accuracy, and Inter-Day and Intra-Day Precision}

The accuracy, and inter-day and intra-day precision of the method were evaluated by assaying ten replicate samples of pharmaceutical form (capsules) with same lamivudine concentration $\left(150 \mathrm{mg} \cdot \mathrm{L}^{-1}\right)$ in three analytical runs. Accuracy was measured as the percentage deviation from the nominal concentration. The inter-day and intraday precision was obtained by analysis of variance (ANOVA) for each test concentration using the analytical run as the grouping variable (see results in Table 1).

\subsection{Analysis of Pharmaceutical Dosage Forms}

\subsubsection{Sample Treatment}

Twenty lamivudine capsules reporting $150 \mathrm{mg}$ of lamivudine were powdered and accurately weighted. The capsule average weight was calculated. An amount of powder equivalent to one average weight was weighted and transferred into a $100 \mathrm{~mL}$ volumetric flask. After sonicating and shaking this mixture for $20 \mathrm{mins}$, it was diluted

Table 1. Results of validation method for determination of lamivudine in commercial drugs.

\begin{tabular}{cc}
\hline Parameters of validation & Results \\
\hline Linearity & $1.15-10.40 \mathrm{mg} \cdot \mathrm{L}^{-1}$ \\
Detection limit & $0.46 \mathrm{mg} \cdot \mathrm{L}^{-1}$ \\
Determination limit & $1.0 \mathrm{mg} \cdot \mathrm{L}^{-1}$ \\
Intra-day precision & $\mathrm{RSD}=1.10 \%$ \\
Inter-day precision & $\mathrm{RSD}=1.40 \%$ \\
Accuracy & $95.15 \%$ \\
\hline
\end{tabular}


with purified water to the mark and filtered at a $0.5 \mu \mathrm{m}$ filter. Then $10 \mathrm{~mL}$ of the filtrate was transferred into a $100 \mathrm{~mL}$ volumetric flask and diluted with Clark-Lubs buffer. The samples, in syrup form $(3 \mathrm{~mL})$ were transferred into a $200 \mathrm{~mL}$ volumetric flask and also diluted with Clark-Lubs buffer.

\subsubsection{Voltammetric Analysis}

A known volume $(10 \mathrm{~mL})$ of the supporting electrolyte solution (0.2 M Clark-Lubs buffer, $\mathrm{pH}$ 2.0) was added to the voltammetric cell and degassed with nitrogen for 2 minutes while stirring. An initial potential $(-1.00 \mathrm{~V})$ was applied to the electrode, while the solution was being stirred. The stirring was then stopped and the voltammogram was recorded at $20 \mathrm{mV} / \mathrm{s}$ by applying a negativegoing potential scan (differential pulse mode; pulse amplitude, $50 \mathrm{mV}$; final potential, $-1.25 \mathrm{~V}$ ). After the background differential pulse voltammograms had been obtained, aliquots of the lamivudine $(0.1 \mathrm{~mL}$ of the stock solution) were introduced. Analysis of the pharmaceutical forms followed the same procedure. In this case, 0.3 $\mathrm{mL}$ of the drug solution was used and the analyses were repeated ten times. All data were obtained at ambient temperature $\left(25^{\circ} \mathrm{C}\right)$.

\section{Results and Discussion}

\subsection{Cyclic Voltammetric Studies}

The effect of scan rate on both the current, $\left(I_{p}\right)$, and potential, $\left(E_{p}\right)$, peaks of lamivudine were studied by cyclic voltammetry. In both cases, an increase in scan rate caused an increase in the $I_{p}$ with a simultaneous negative shift of $E_{p}$.

Figure 1 shows a typical cyclic voltammogram for 5 $\mathrm{mg} \cdot \mathrm{L}^{-1}$ lamivudine in a $0.2 \mathrm{M}$ Clark-Lubs buffer solution (pH 2.0) using $100 \mathrm{mV} / \mathrm{s}$ as a scan rate. The lamivudine yields a well-defined reduction peak at $-1.18 \mathrm{~V}$ during the forward cathodic scan. No peaks are observed in the anodic branch indicating irreversibility of the electrodic reaction. Hence, the reduction peak at $-1.18 \mathrm{~V}$ was chosen for subsequent differential pulse voltammetric determinations, including the quantification of lamivudine in antiretroviral drug.

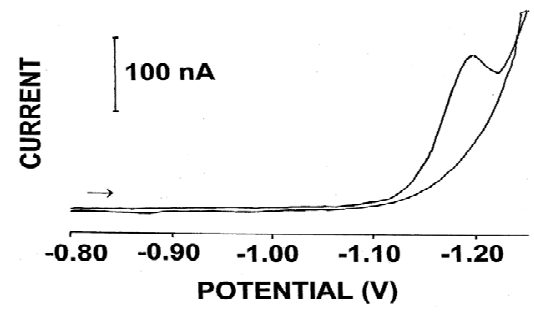

Figure 1. Cyclic voltammogram of the lamivudine $\left(5 \mathrm{mg} \cdot \mathrm{L}^{-1}\right)$ in a solution of $0.2 \mathrm{M}$ Clark-Lubs buffer (pH 2.0). Scan rate, $100 \mathrm{mV} \cdot \mathrm{s}^{-1}$. Pulse amplitude, $50 \mathrm{mV}$.

\section{2. pH Dependence}

The influence of $\mathrm{pH}$ on the lamivudine reduction process was studied. The Britton-Robinson buffer solution was used in the $\mathrm{pH}$ range from 2.0 to 11.5 and the lamivudine reduction peak appeared only from 2.0 to $5.5 \mathrm{pH}$. The current peak, $\left(I_{p}\right)$, versus $\mathrm{pH}$ plot shows that the lamivudine peak current is maximized at a low $\mathrm{pH}$. These results suggest the importance of an acid medium for production of intermediates in the mechanism of the lamivudine electrochemical reaction. The effects of the other different buffer solutions, such as acetate and Clark-Lubs buffer, in the lamivudine peak, also were tested. The 0.2 M Clark-Lubs buffer solution $(\mathrm{pH}=2.0)$ showed better compromise between sensitivity and resolution and was used throughout the further study. The $\mathrm{pH}$ also affects the lamivudine reduction peak potential, $\left(E_{p}\right)$. When the $\mathrm{pH}$ values were increased from 2.0 to 5.5, a cathodic shift of the lamivudine potential peak was observed. Probably these results indicate the participation of protons in the electrodic process. The slope obtained for this linear relation was of $60.7 \mathrm{mV} \cdot \mathrm{pH}^{-1}$, indicating the consumption of an identical number of protons and electrons. An imperceptible intersection could be observed in $\mathrm{pH} 4.5$, indicating the presence of two linear regions. This inter-

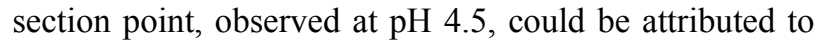
the $\mathrm{pK}_{1}$ of lamivudine. A value of 4.60 is reported in the literature as $\mathrm{pK}_{1}$ of cytosine [17].

\subsection{Effect of Instrumental Parameters}

Several instrumental parameters such as pulse amplitude, drop size, stirring rate, and scan rate which directly affect the lamivudine voltammetric response were optimized. The effect of the pulse amplitude on the differential pulse peak current (at $-1.16 \mathrm{~V}$ ) was examined over the 10 to $100 \mathrm{mV}$ region. The results showed a better performance of current peak, $\left(I_{p}\right)$ and of the half-width, $\left(b_{1 / 2}\right.$ of 62.2 $\mathrm{mV}$ ), at $50 \mathrm{mV}$. The effect of the drop area was examined over 0.15 to $0.60 \mathrm{~mm}^{2}$ and the greatest resolution peaks were observed at $0.43 \mathrm{~mm}^{2}\left(b_{1 / 2}\right.$ of $\left.60.5 \mathrm{mV}\right)$. For forced convection to increase the rate of transport of lamivudine molecules to the surface electrode, $2000 \mathrm{rpm}$ offers better signal-to-background characteristics and are recommended for the determination of lamivudine. The lamivudine current peak $\left(I_{p}\right)$ increasing with the scan rate (from 10 to $50 \mathrm{mv} / \mathrm{s}$ ). The scan rate of $20 \mathrm{mV} / \mathrm{s}$ would be the best compromise when considering the sensitivity, resolution and speed requirements and was used throughout. (Other conditions: $10 \mathrm{mg} \cdot \mathrm{L}^{-1}$ of the lamivudine, pulse amplitude, $50 \mathrm{mV}$ ).

\subsection{Validation Method}

The stock solution of lamivudine in $\mathrm{HCL}, 2 \mathrm{M}$ (at $25^{\circ} \mathrm{C}$ ) was stable for at least two weeks compared to the freshly 
prepared samples. The specificity of the assay was evaluated by analysis of three different lots of pharmaceutical samples (capsules). None of the three samples yielded peaks that would interfere with quantification of either lamivudine. Additional samples, which were spiked with other retroviral zidovudine (AZT) and zalcitabine (DDC), were subjected to the same procedures and voltammetric analysis. The presence of zalcitabine (DDC) enhanced the lamivudine peak. The zidovudine (AZT) yields a well-defined reduction peak at $-0.96 \mathrm{~V}$ (far lamivudine) and zalcitabine (DDC) at $-1.18 \mathrm{~V}$ (near lamivudine) vs $\mathrm{Ag} / \mathrm{AgCl}$ during forward cathodic scan. Concentrations of $100 \mathrm{mg} \cdot \mathrm{L}^{-1} \mathrm{Fe}^{3+}, \mathrm{Cu}^{2+}, \mathrm{Zn}^{2+}, \mathrm{Li}^{+}, \mathrm{Pb}^{2+}, \mathrm{Cd}^{2+}, \mathrm{Ni}^{2+}$, $\mathrm{Co}^{2+}$, and $\mathrm{Cr}^{3+}$ did not interfere with the determination of $23 \mathrm{mg} \cdot \mathrm{L}^{-1}$ lamivudine. Most likely these ions do not form complexes with lamivudine. The others results produced by the validation method are show in Table $\mathbf{1}$, indicating that the proposed voltammetric method can be successfully used as an analytical method to determine lamivudine in pharmaceuticals forms.

\subsection{Determination of Lamivudine in Pharmaceutical Formulations}

Figure 2 illustrates the response to successive standard additions of lamivudine, each addition affecting a 1.15 $\mathrm{mg} \cdot \mathrm{L}^{-1}$ increase in concentration. Well defined differential pulse peaks are observed at the $1.15-10.40 \mathrm{mg} \cdot \mathrm{L}^{-1}$ concentration level. The resulting plot of peak current vs concentration is linear (slop $43.3 \mathrm{nA} / \mathrm{mg} \cdot \mathrm{L}^{-1}$; correlation coefficient, 0.999). The differential pulse response of lamivudine is highly reproducible. Five successive mea-

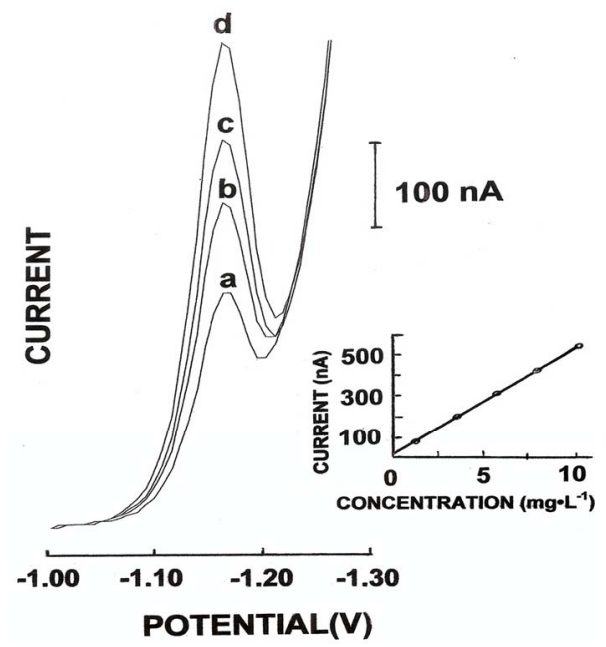

Figure 2. Differential pulse voltammograms obtained for solutions of increasing lamivudine concentration; 2.30(a), 4.60(b), 6.90(c) and 9.20(d) $\mathrm{mg} \cdot \mathrm{L}^{-1}$. Also shown is the resulting calibration plot $\left(1.15-10.40 \mathrm{mg} \cdot \mathrm{L}^{-1}\right)$. Other conditions: solution of $0.2 \mathrm{M}$ Clark-Lubs buffer (pH 2.0) as supporting electrolyte. Scan rate, $20 \mathrm{mV} \cdot \mathrm{s}^{-1}$. Pulse amplitude, $50 \mathrm{mV}$. surements for each point of the analytical curve yielded standard deviations of $0.080,0.092,0.180,0.047$ and 0.179 , respectively. A detection limit of $0.46 \mathrm{mg} \cdot \mathrm{L}^{-1}$ and a quantification limit of $1.0 \mathrm{mg} \cdot \mathrm{L}^{-1}$ also were estimated.

These results were used for calculating the amount of antiretroviral drug lamivudine present in the analyzed solutions. The average result obtained for lamivudine determination in pharmaceutical capsules and syrup was 155.1 $\mathrm{mg} /$ capsule and $9.70 \mathrm{mg} \cdot \mathrm{mL}^{-1}$ in syrup, corresponding to $103.4 \%$ and $97.0 \%$, respectively, of the declared amount (150 mg/capsule and $10 \mathrm{mg} \cdot \mathrm{mL}^{-1}$ in syrup). The relative standard deviation was $0.92 \%$ and $1.10 \%$, respectively, indicating adequate precision of the proposed method.

\section{Conclusion}

The present study describes an effective means for the determination of trace levels of antiretroviral drug lamivudine. Among the reported analytical methods for lamivudine, the described procedure is distinguished by its inexpensive cost and lowest detection limit. The statistically evaluated results have shown that the method is specific, precise, accurate, and robust ensuring the analytical safety of lamivudine (3TC) determination in pharmaceutical products. Our laboratory has been investigating the utilization of preadsorptive voltammetric techniques which could be used to the improvement in sensitivity and selectivity of the lamivudine metabolites determination. The same voltammetric procedure also can be extended to many other drugs (zidovudine, efavirenz and nevirapine) with antiretroviral activity for the treatment of HIV patients.

\section{Acknowledgements}

The authors gratefully acknowledge the Fiocruz, CNPq and CAPES of the Government of Brazil and PUC-Rio for their support of this work.

\section{REFERENCES}

[1] K. Parfitt, "The Complete Drug Reference," 32nd Edition, Pharmaceutical Press, London, 1999, pp. 629-630.

[2] C. M. Perry and D. Faulds, "Lamivudine. A Review of Its Antiviral Activity, Pharmacokinetic Properties and Therapeutic Efficacy in the Management of HIV Infection," Drugs, Vol. 53, No. 4, 1997, pp. 657-680. doi:10.2165/00003495-199753040-00008

[3] E. De Clercq, "Antiviral Drugs: Current State of the Art," Journal of Clinical Virology, Vol. 22, No. 1, 2001, pp. 73-89. doi:10.1016/S1386-6532(01)00167-6

[4] J. W. Beach, "Chemotherapeutic Agents for Human Immunodeficiency Vírus Infection: Mechanism of Action, Pharmacokinetics, Metabolism, and Adverse Reactions," Clinical Therapeutics, Vol. 20, No. 1, 1998, pp. 2-25. doi:10.1016/S0149-2918(98)80031-3 
[5] D. A. Kumar, G. S. Rao and J. V. L. N. S. Rao, "Simultaneous Determination of Lamivudine, Zidovudine and Abacavir in Tablet Dosage Forms by HPLC Method," E-Journal of Chemistry, Vol. 7, No. 1, 2010, pp. 180-184. doi: $10.1155 / 2010 / 473798$

[6] P. Chandra, A. S. Rathore, L. Sathivanarayanan and K. R. Mahadik, "Application of High-Performance Thin-Layer Chromatographic Method for the Simultaneous Determination of Lamivudine and Tenofovir Disoproxilfumarate in Pharmaceutical Dosage Form," Journal of the Chilean Chemical Society, Vol. 56, No. 2, 2011, pp. 702-705. doi:10.4067/S0717-97072011000200017

[7] S. Notari, M. Sergi, C. Montesano, J. Ivanovic, P. Narciso, L. P. Pucillo and P. Ascenzi, "Simultaneous Determination of Lamivudine, Lopinavir, Ritonavir, and Zidovudine Concentration in Plasma of HIV-Infected Patients by HPLCMS/MS," IUBMB Life, Vol. 64, No. 5, 2012, pp. 443449. doi:10.1002/iub. 1025

[8] A. T. C. Oliveira, D. P. Santana, J. R. B. Alencar, L. A. S. Ribas, D. B. Monteiro, B. A. Santos, A. D. P. Oliveira and A. K. M. Santana, "Cleaning Validation Applied to the Production of Antiretroviral Drugs: Determination of Zidovudine and Lamivudine Residues on Manufacturing Equipment," Latin American Journal of Pharmacy, Vol. 31, No. 2, 2012, pp. 315-320.

[9] C. Parthiban, M. B. Raju, M. Sudhakar and D. S. Kumar, "Simultaneous Estimation and Validation for Determination of Lamivudine and Zidovudine in Human Plasma by LCMS/MS Method," E-Journal of Chemistry, Vol. 9, No. 2, 2012, pp. 598-607. doi:10.1155/2012/716963

[10] J. E. Rower, B. Klein, L. R. Bushman and P. L. Anderson, "Validation of a Sensitive LC/MS/MS Method for the
Determination of Zidovudine and Lamivudine in Human Plasma," Biomedical Chromatography, Vol. 26, No. 1, 2012, pp. 12-20. doi:10.1002/bmc.1617

[11] K. Basavaiah, B. C. Somashekar and V. Ramakrishna, "Rapid Titrimetric and Spectrophotometric Assay Methods for the Determination of Lamivudine in Pharmaceuticals Using Iodate and Two Dyes," Journal of Analytical Chemistry, Vol. 62, No. 6, 2007, pp. 542-548. doi:10.1134/S1061934807060081

[12] A. B. Babu, G. Ramu, C. M. Krishna, S. B. Reddy and C. Rambabu, "Spectrophotometric determination of lamivudine in Pure and Tablet Forms," E-Journal of Chemistry, Vol. 9, No. 2, 2012, pp. 569-575. doi: $10.1155 / 2012 / 627617$

[13] B. Dogan, B. Uslu, S. Suzen and S. A. Ozkan, "Electrochemical Evaluation of Nucleoside Analogue Lamivudine in Pharmaceutical Dosage Forms and Human Serum," Electroanalysis, Vol. 17, No. 20, 2005, pp. 1886-1894. doi:10.1002/elan.200503307

[14] R. Jain, N. Jadon and K. Radhapyari, "Cathodic Adsorptive Stripping Voltammetric Studies on Lamivudine: An Antiretroviral Drug," Journal of Colloid and Interface Science, Vol. 313, No. 1, 2007, pp. 254-260. doi:10.1016/j.jcis.2007.04.003

[15] INMETRO, “Orientação Sobre Validação de Métodos de Ensaios Químicos: DOQ-CGCRE-008. Revisão 02. Rio de Janeiro," 2007.

[16] The United States Pharmacopeia, "USP 31 NF 26. Rockville: United States Pharmacopeia Convention,” 2008.

[17] “The Merck Index," 13th Edition, Merck \& Co. Inc., White House Station, 2001. 